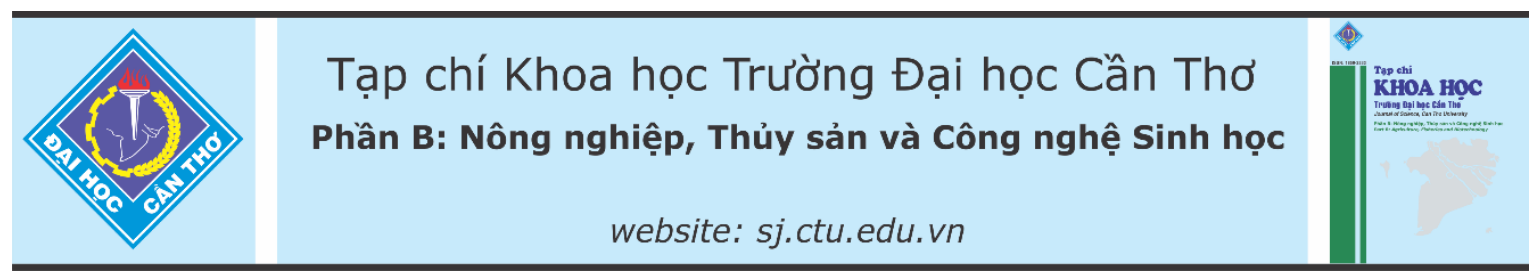

DOI:10.22144/ctu.jvn.2021.021

\title{
ĐA DẠNG HÌNH THÁI THEO GIÓ́I TÍNH CỦA CÁ BA KỲ ĐỎ (Cyclocheilichthys apogon)
}

Dương Thúy Yên ${ }^{1 *}$, Trần Thị Vân Phụng ${ }^{2}$ và Nguyễn Thị Ngọc Trân ${ }^{1}$

${ }^{1}$ Khoa Thủy sản, Truờng Đại học Cần Tho

${ }^{2}$ Lớp Nuôi trồng thủy sản K42, Khoa Phát triển Nông thôn, Truờng Đại học Cần Thơ

*Nguoòi chịu trách nhiệm về bài viết: Dương Thúy Yên (email: thuyyen@ctu.edu.vn)

\section{Thông tin chung:}

Ngày nhận bài: 01/08/2020

Ngày nhận bài sủa: 01/12/2020

Ngày duyệt đăng: 27/02/2021

\section{Title:}

Sexual dimorphism in morphology of

Cyclocheilichthys apogon

\section{Tù khóa:}

Cá ba kỳ đỏ, Cyclocheilichthys apogon, hìn thái, khác biệt theo giới tính, sinh truớng

\section{Keywords:}

Beardless barb,

Cyclocheilichthys apogon, morphology, sexual dimorphism.

\section{ABSTRACT}

This study was aimed to identify similarities and differences in growth and morphological characteristics of beardless barb (Cyclocheilichthys apogon) between two sexes. Fish samples $(n=244)$ were collected in canals surrounding U Minh Thuong, Kien Giang province from July 2019 to March 2020. Length-weight relationship (LWR) and morphological characteristics including countable traits (number of fin spines and rays) and morphometric indices (ratios of body and head measurements to standard length and head length) were analyzed. Females have larger sizes than males $(P<0.01)$. The growth coefficient $(b)$ of $L W R\left(W=a L^{b}\right)$ has a trend of $\geq 3$ in females and $\leq 3$ in males. Countable traits, body shape and color are similar between females and males. However, 15 out of 20 morphometric indices are different between two sexes $(P<0.05$ or $P<0.01)$, in which obvious differences are in head morphology and body depth. Females have higher body depth, and shorter but wider and deeper head. In contrast, males have larger dorsal fin length and anal fin base. Above differences between females and males can be related to spawning and movement behaviors of Cyclocheilichthys apogon.

\section{TÓM TẮT}

Nghiên cứu này nhằm tìm hiểu nhũng điểm giống và khác nhau về đặc điểm sinh truơong và hình thái của cá ba kỳ đỏ (Cyclocheilichthys apogon) theo giới tính. Mẫu cá được thu $(n=244)$ ở kênh bao quanh $U$ Minh Thurơng - Kiên Giang, tù tháng 7/2019 đến tháng 3/2020. Mối quan hệ chiều dài-khối lượng và đặc điểm hình thái gồm chi tiêu đếm (số luợng tia, gai ở vi) và chỉ tiêu sinh trắc (tỉ lệ số đo phần thân và đầu trên chiều dài chuẩn và chiều dài đầu) được phân tích. Cá cái có kích cỡ lớn hơn cá đục $(P<0,01)$. Hệ số sinh truơơng (b) của mối quan hệ chiều dài-khối lương $\left(W=a L^{b}\right)$ có $x u$ huớng $\geq 3$ ơ cá cái và $\leq 3$ ở con đụcc. Các chi tiêu đếm, hình dạng co thể và màu sắc bên ngoài giống nhau giũua hai giới. Tuy nhiên, đa số các chỉ tiêu sinh trắc (15/20 chi tiêu) khác biệt có ý nghĩa giữa cá đực và cá cái $(P<0,05$ hoạc $P<0,01)$, trong đó khác biệt rõ nhất ơ phần đầu và cao thân. Cá cái có tỉ lẹ cao thân lớn hơn, đầu ngắn hơn nhưng rộng và cao hơn cá đực. Ngược lại, cá đực có chiều dài tia vi lung và dài gốc vi hậu môn lớn hơn cá cái. Những điểm khác biệt trên có thể liên quan đến đặc điểm sinh sản và di chuyển của hai giới tính. 


\section{GIỚI THIỆU}

Cá ba kỳ đỏ (Cyclocheilichthys apogon) thuộc họ cá chép Cyprinidae là một trong những loài cá phổ biến ở Đồng bằng Sông Cửu Long (ĐBSCL) và một số quốc gia ở khu vực Đông Nam Á (Kottelat, 2001; Rainboth, 1996). Môi trường sống của chúng là kênh, mương hoặc những thủy vực nước đứng hoặc nước chảy chậm (Rainboth, 1996). Cá ba kỳ đỏ có giá trị kinh tế cao, là nguồn thực phẩm và là loài cá cảnh được ưa thích vì cơ thể cá có màu sắc đẹp. Hình thái bên ngoài của cá ba kỳ đỏ dễ dàng được phân biệt với các loài cùng họ cá chép nhờ các đặc điểm đặc trưng như gốc vi đuôi có một đốm đen hình bầu dục hoặc tròn và các vi (vi hậu môn, vi lưng và vi đuôi) có màu đỏ (Trương Thủ Khoa và Trần Thị Thu Hương, 1993). Nghiên cứu về hình thái phân loại cá ba kỳ đỏ còn rất ít. Những thông tin trên Fishbase chỉ nêu một số đặc điểm nhận diện loài, chủ yếu từ nghiên cứu của Rainboth (1996) và Kottelat (2001). Trong nước có nghiên cứu của Mai Đình Yên và ctv. (1992) và Trương Thủ Khoa và Trần Thị Thu Hương (1993), song với số mẫu ít (4 đến 5 mẫu), do đó chưa đánh giá được sự đa dạng của các chỉ tiêu hình thái, đặc biệt là các chỉ tiêu sinh trắc. Hơn nữa, trong các tài liệu công bố, chưa có nghiên cứu nào đề cập đến sự khác biệt về hình thái giữa cá đực và cá cái.

Sự thay đổi về hình thái theo giới tính chủ yếu là những đặc điểm sinh dục thứ cấp như màu sắc, hình dạng và kích cỡ cơ thể (Kitano et al., 2007; Parker, 1992), hình dạng và chiều dài các vi (Low \& Lim, 2012) hay hình dạng đầu (Aguirre \& Akinpelu, 2010). Những khác biệt này là kết quả của quá trình tiến hóa dưới ảnh hưởng của nhiều yếu tố như phương thức sinh sản, mức độ cạnh tranh trong mỗi giới và giữa hai giới, mối quan hệ bù trừ giữa một số đặc điểm như tăng trưởng và khả năng sống,...(Mei \& Gui, 2015; Parker, 1992). Vì vậy, những nghiên cứu về khác biệt hình thái giữa hai giới tính giúp hiểu thêm về sự đa dạng và thích nghi của sinh vật.

Nghiên cứu này nhằm tìm ra những điểm giống và khác nhau giữa cá cái và đực về đặc điểm sinh trưởng và hình thái, nhằm bổ sung thông tin về đặc điểm sinh học của loài, làm cơ sở cho các nghiên cứu tiếp theo.

\section{PHƯƠNG PHÁP NGHIÊN CÚU}

\subsection{Phương pháp thu mẫu}

Mẫu cá ba kỳ đỏ được thu mỗi tháng từ tháng 7/2019 đến tháng 3/2020 bằng lưới vó, đặt ở các kênh bao quanh Vườn Quốc gia U Minh Thượng. Sau khi thu, mẫu được bảo quản lạnh và vận chuyển về Phòng thí nghiệm thuộc Khoa Thủy sản, Trường Đại học Cần Thơ để tiến hành phân tích.

\subsection{Phương pháp phân tích hình thái}

Cá ba kỳ đỏ được phân biệt so với các loài cá khác thuộc họ cá chép bằng đặc điểm các vi màu đỏ cam và có đốm đen ở cuống đuôi (Trương Thủ Khoa và Trần Thị Thu Hương, 1993). Sau khi phân loại cá, mỗi cá thể được đánh dấu bằng ký hiệu liên tục theo từng đợt thu mẫu và chụp hình có thước đo. Khối lượng tổng $(\mathrm{W})$ và các chỉ tiêu hình thái gồm chỉ tiêu đo, đếm được ghi nhận theo hướng dẫn của Rainboth (1996) và Phạm Thanh Liêm và Trần Đắc Định (2004). Sau đó cá được xác định giới tính bằng cách giải phẫu và quan sát tuyến sinh dục. Các chỉ tiêu đếm gồm số lượng các tia và gai vi lưng, vi ngực, vi bụng và vi hậu môn. Tổng cộng 22 chỉ tiêu đo gồm 17 chỉ tiêu phần thân và 5 chỉ tiêu phần đầu (Hình 1). Tất cả các chỉ tiêu trên được đo trên hình ảnh các cá thể đã chụp trước đó bằng phần mềm ImageJ (Schneider et al., 2012). Đầu tiên, tỉ lệ đo được thiết lập tương đương với đơn vị $1 \mathrm{~cm}$ trên thước đo trên từng hình chụp. Phần mềm sẽ xuất ra số liệu các số đo dựa trên khoảng cách các vị trí của từng chỉ tiêu đo được mô tả trong Hình 1. 


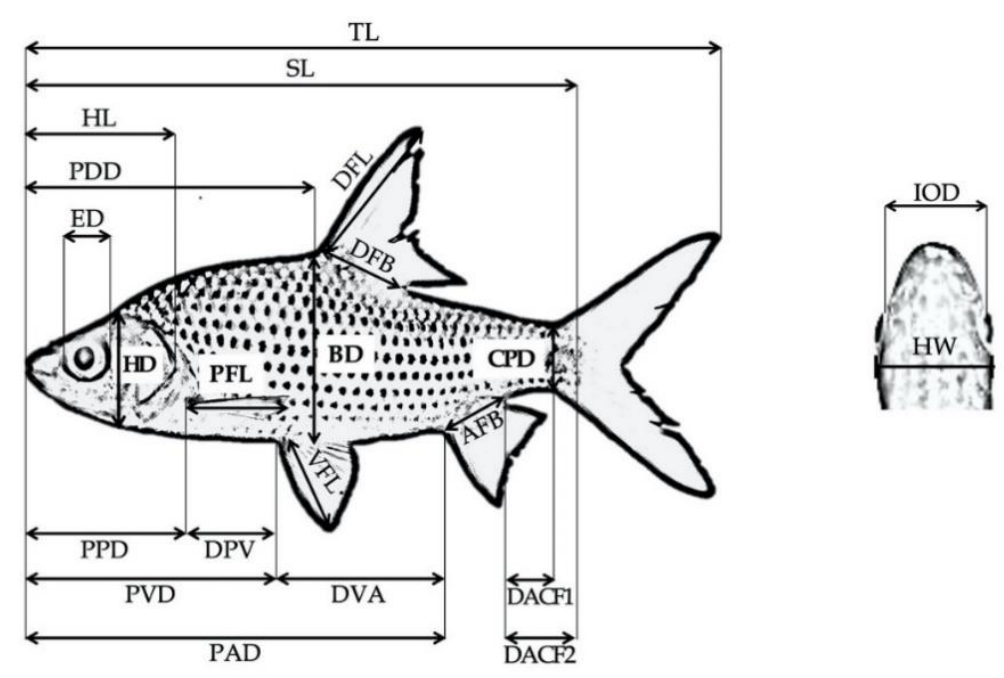

Hình 1. Các chỉ tiêu đo phần thân và phần đầu của cá ba kỳ đỏ

Ghi chú: Muời bảy chỉ tiêu đo phần thân gồm: chiều dài tổng (TL), chiều dài chuẩn (SL), cao thân (BD), cao cuống đuôi (CPD), dài cuống đuôi 1 (DACF1), dài cuống đuôi 2 (DACF2), khoảng cách trước vi lưng (PDD), khoảng cách trước vi ngực (PPD), khoảng cách truớc vi bụng (PVD), khoảng cách truớc vi hậu môn (PAD), khoảng cách giữa vi ngực và vi bụng (DPV), khoảng cách giũ̃a vi bụng và vi hậu môn (DVA), chiều dài vi lung (DFL), chiều dài gốc vi lung (DFB), chiều dài vi ngục (PFL), chiều dài vi bung (VFL), chiều dài gốc vi hậu môn (AFB). Năm chỉ tiêu phần đầu (dài đầu $(H L)$, cao đầu $(H D)$, đuờng kính mắt (ED), rộng đầu $(H W)$, khoảng cách 2 mắt (IOD).

\subsection{Phương pháp xử lý số liệu}

Mối quan hệ chiều dài (tổng) và khối lượng được thể hiện qua phương trình:

$$
\mathrm{W}=\mathrm{aL}^{\mathrm{b}}
$$

Trong đó, $\mathrm{W}$ là khối lượng tổng $(\mathrm{g})$ và $\mathrm{L}$ là chiều dài tổng của cơ thể cá $(\mathrm{cm})$. Phương trình trên được chuyển sang dạng tuyến tính bằng cách lấy logarit hai vế:

$$
\operatorname{Ln}(\mathrm{W})=\operatorname{Ln}(\mathrm{a})+\mathrm{bLn}(\mathrm{L})
$$

Hệ số $\mathrm{a}, \mathrm{b}$ của phương trình sinh trưởng trên được ước lượng và so sánh giữa cá đực và cá cái bằng phương pháp kiểm định mô hình tuyến tính:

$$
\mathrm{Ln}(\mathrm{W})=\text { Giới_tính } * \operatorname{Ln}(\mathrm{L})
$$

Các chỉ tiêu sinh trắc được so sánh giữa hai giới tính bằng phương pháp kiểm định $\mathrm{t}$-test. Phân tích thống kê được thực hiện trên phần mềm $\mathrm{R}$ ( $\mathrm{R}$ Core Team, 2017) và SPSS 20.0.

\section{KẾT QUẢ VÀ THẢO LUẬN \\ 3.1. Hình dạng bên ngoài và các chỉ tiêu đếm của cá ba kỳ đỏ}

Cá ba kỳ đỏ có một đốm đen ở cuống đuôi và các vi có màu đỏ cam, thân cá dẹp bên, khắp thân được bao bọc bởi vảy tròn ngoại trừ phần đầu không có vảy, hai bên thân có ánh bạc kèm theo những chấm đen chạy song song và dọc thân. Về các chỉ tiêu đếm, cá ba kỳ đỏ có số lượng gai và tia ở các vi như sau: vi lưng là III, 8 ; vi ngực là $I, 13$; vi bụng là $I, 9$ và vi hậu môn III,5. Kết quả này phù hợp với nghiên cứu trước đây (Mai Đình Yên và ctv., 1992; Trương Thủ Khoa và Trần Thị Thu Hương, 1993). Hình dạng bên ngoài của cá cái và cá đực rất giống nhau (Hình 2) và gần như không thể phân biệt, trừ những cá thể cái thành thục có bụng to. Màu sắc đỏ cam ở các vi của chúng cũng giống nhau, khác với một số loài khác có sự chọn lọc giới tính, con đực thường có màu sắc vi sặc sỡ hơn con cái như họ cá bảy màu Poeciliidae (Endler, 1984). 


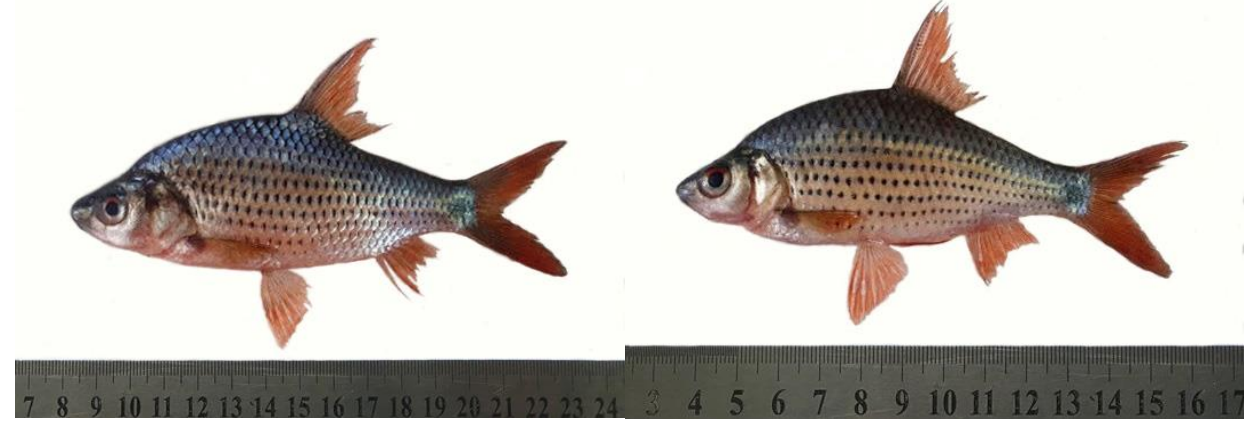

Hình 2. Hình dạng bên ngoài của cá ba kỳ đỏ cái (trái) và đực (phải)

3.2. Mối quan hệ chiều dài - khối lượng của cá ba kỷ đỏ ở hai giới tính

Trong số 244 mẫu cá thu được, khoảng dao động kích cỡ của con cái (từ 6,91 đến $88,58 \mathrm{~g}$ ) và con đực $(6,47$ đến $82,03 \mathrm{~g})$ tương đương nhau nhưng khối lượng trung bình của cá cái $(36,9 \pm 13,9 \mathrm{~g})$ lớn hơn có ý nghĩa so với cá đực $(25,4 \pm 12,7 \mathrm{~g})(\mathrm{P}<0,05)$.

Mối quan hệ chiều dài - khối lượng của cá ba kỳ đỏ ở con cái và con đực (Hình 3 ) thể hiện qua hai phương trình tương ứng là $\mathrm{W}_{\mathrm{C}}=0,012 \mathrm{~L}^{3,032}$ (với $\mathrm{R}^{2}=0,93, \mathrm{n}=129$ mẫu) và $\mathrm{W}_{Ð}=0,014 \mathrm{~L}^{2,922}$ (với $\mathrm{R}^{2}=0,93, \mathrm{n}=115$ mẫu). Hệ số $\mathrm{b}$ ở con cái $( \pm \mathrm{SE})$ là $3,032 \pm 0,075$ lớn hơn con đực $(2,922 \pm 0,081)$, tuy nhiên sự khác biệt này không có ý nghĩa $(\mathrm{P}>0,05)$. Hệ số $\mathrm{b}$ tính chung cho cả hai giới là $3,090 \pm 0,055$ (khoảng tin cậy $95 \%$ của $b$ từ 2,98 đến 3,20 ), khác 3 không có ý nghĩa $(\mathrm{P}>0,05)$.

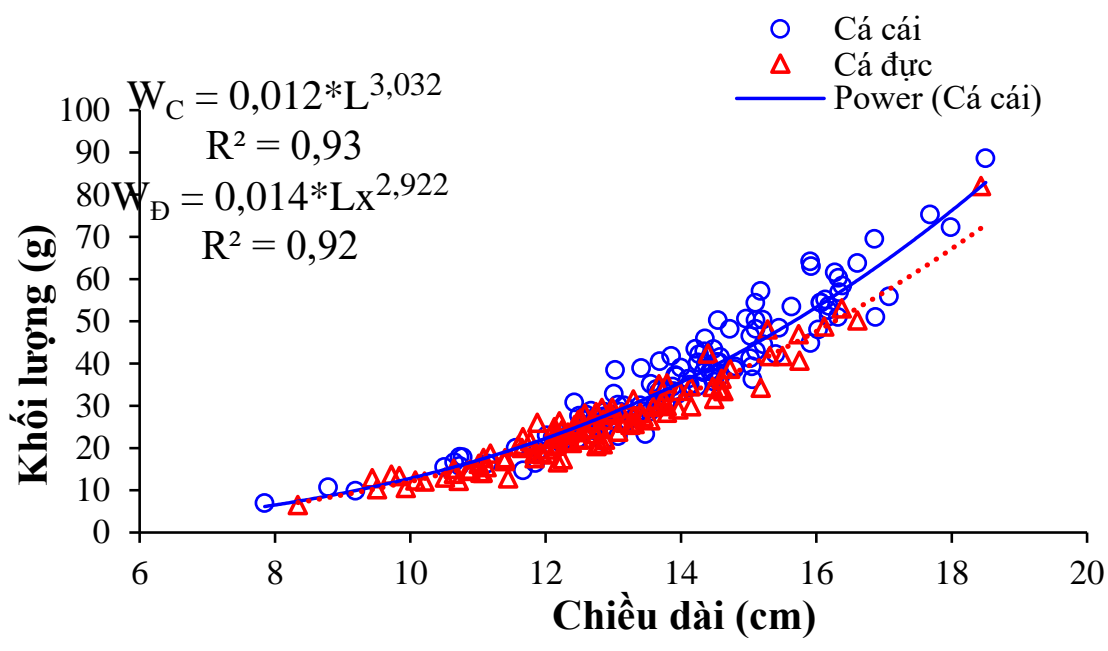

Hình 3. Mối quan hệ chiều dài $(\mathrm{L})$ và khối lượng $(\mathrm{W})$ của ba kỳ đỏ

Hệ số $\mathrm{b}$ nói lên đặc điểm tăng trưởng và độ béo của cá. Một loài có $b=3$ được xem là tăng trưởng đồng đều và mẫu cá nhỏ có cùng dạng cơ thể và điều kiện "béo" như mẫu cá lớn (Le Cren, 1951; trích bởi Froese, 2006). Mặc dù cá ba kỳ đỏ có b khác 3 không có ý nghĩa, song có xu hướng $>3$ (từ 2,98 đến 3,20 ) nghĩa là, cá có xu hướng tăng về khối lượng (thường là do tăng về độ béo hay độ dày của cơ thể) hơn tăng về chiều dài. Xu hướng này chủ yếu thể hiện ở cá cái (b dao động từ 2,88 đến 3,18 ), trong khi ở cá đực $\leq 3$ (2,76 đến 3,08). Theo Froese (2006), khoảng biến động $\mathrm{b}$ của 1.773 loài cá đã công bố là từ 2,5 đến 3,5 , trong đó $82 \%$ số loài có $b>3$ và giá trị giữa (median) của $\mathrm{b}$ là 3,03 , chứng tỏ nhiều loài có khuynh hướng tăng trưởng về khối lượng hay độ dày, độ béo của cơ thể.

Hệ số $\mathrm{b}$ của cá ba kỳ đỏ trong nghiên cứu này thấp hơn kết quả trong một số nghiên cứu ở những khu vực khác nhau ở Malaysia theo tổng hợp của Radhi et al. (2017). Kết quả ở Malaysia cho thấy ba kỳ đỏ có giá trị $b>3$, như cá ở sông Kerian có $b=3,51$ ( $\mathrm{n}=46$ mâ̂u); hồ chứa nước Temengor có $\mathrm{b}=3,16$ 
( $n=233$ ); sông Pahang với 203 mẫu có $b=3,22$; sông Tembeling (thuộc Pahang) có 215 mẫu với $b=3,15$; sông ở Temerloh có 48 mẫu với $b=3,05$. Sự khác biệt giá trị b của cá ba kỳ đỏ giữa các nơi phân bố hoặc giữa các nghiên cứu cũng tương tự như ghi nhận ở một số loài cá (Froese, 2006). Đó là do sự khác biệt về điều kiện môi trường sống (ảnh hưởng đến thức ăn sẵn có và hoạt động bắt mồi của cá,...), mùa vụ sinh sản, giai đoạn phát triển của cá,...(Froese, 2006). Trong nghiên cứu này, kết quả cho thấy giới tính cũng ảnh hưởng một phần đến hệ số $\mathrm{b}$ của phương trình quan hệ chiều dài - khối lượng. Tương tự, một số loài cá thuộc họ cá tráp (bộ cá vược) có sự khác biệt hệ số b giữa cá cái và đực như Mullus surmuletus, Pagellus acarne (Karakulak et al., 2006).

\subsection{So sánh chỉ tiêu sinh trắc giữa cá đực và cá cái}

Trong 20 chỉ tiêu đo được tính tỉ lệ so với chiều dài chuẩn $(\mathrm{SL}, 16$ chỉ tiêu) và chiều dài đầu $(\mathrm{HL}, 4$ chỉ tiêu), cá cái và cá đực khác nhau có ý nghĩa $(\mathrm{P}<0,05)$ ở 15 chỉ tiêu, chiếm $75 \%$ (Bảng 2). Năm chỉ tiêu giống nhau bao gồm chiều cao cuống đuôi (CPD), chiều dài cuống đuôi (DACF1 và DACF2) và đường kính mắt $(\mathrm{ED})$. Các chỉ tiêu thể hiện rõ sự khác biệt $(\mathrm{P}<0,01)$ giữa hai giới bao gồm chiều cao thân, hình dạng đầu và chiều dài vi và gốc vi. $C u ̣$ thể, cá cái có tỉ lệ cao thân $(\mathrm{BD} / \mathrm{SL})$ lớn hơn cá đực. Đầu của cá cái rộng (HW) hơn, cao hơn (HD) nhưng ngắn hơn (HL) so với cá đực. Do cá cái có chiều rộng đầu lớn nên khoảng cách hai mắt (IOD) của cá cái cũng lớn hơn $4,41 \%$ so với cá đực. Khoảng cách trước vi bung của cá cái so với chiều dài chuẩn (PVD/SL) là 19,0\%, lớn hơn so với 17,8\% ở cá đực. Ngược lại, chiều dài vi lưng (DFL) và gốc vi hậu môn (AFL) của cá đực lớn hơn $5,11 \%$ và $6,14 \%$ so với cá cái. Trong nghiên cứu này, phần lớn các cá thể (khoảng $80 \%$ ) ở giai đoạn trưởng thành (có tuyến sinh dục ở giai đoạn III và IV (số liệu chưa công bố)), còn lại là tiền trưởng thành với kích cỡ nhỏ nhất từ $6,5 \mathrm{~g}$ (Bảng 2).

Bảng 2. Các chỉ tiêu sinh trắc của cá ba kỳ đỏ

\begin{tabular}{|c|c|c|c|c|c|c|}
\hline \multirow[t]{2}{*}{ Chỉ tiêu } & $\begin{array}{r}\text { Cá cái } \\
(\mathrm{n}=129)\end{array}$ & $\begin{array}{c}\text { Cá đực } \\
(\mathrm{n}=115)\end{array}$ & Chung & $\begin{array}{r}\% \text { chênh } \\
\text { lệch }\end{array}$ & \multirow[t]{2}{*}{$\begin{array}{r}\text { Mai Đình Yên'1 } \\
(\mathbf{n}=5)\end{array}$} & \multirow[t]{2}{*}{$\begin{array}{r}\text { TT Khoa \& } \\
\text { TTT Hưong } \\
(n=4)\end{array}$} \\
\hline & $\mathbf{A}$ & B & & $100 *(A-B) / A$ & & \\
\hline Khối lượng(g) & $6,9-88,6$ & $6,5-82,0$ & & & & \\
\hline Chiều dài $(\mathrm{cm})$ & $7,8-18,5$ & $8,3-18,4$ & & & $4,8-11,5$ & $7,8-11,5$ \\
\hline \multicolumn{7}{|c|}{ Tỉ lệ so với chiều dài chuấn (SL, \%) } \\
\hline $\mathrm{BD}$ & $36,7 \pm 1,7$ & $35,3 \pm 1,5$ & $36,0 \pm 1,7$ & $3,72 * *$ & 43 & 38,5 \\
\hline CPD & $12,2 \pm 0,5$ & $12,1 \pm 0,6$ & $12,2 \pm 0,6$ & 0,66 & & \\
\hline DACF1 & $11,7 \pm 1,2$ & $11,7 \pm 1,3$ & $11,7 \pm 1,3$ & $-0,45$ & & \\
\hline $\mathrm{DACF} 2$ & $15,8 \pm 1,2$ & $15,6 \pm 1,3$ & $15,7 \pm 1,2$ & 1,24 & & \\
\hline PDD & $53,7 \pm 1,7$ & $52,5 \pm 1,7$ & $53,1 \pm 1,8$ & $2,16^{* *}$ & & \\
\hline PPD & $25,2 \pm 1,7$ & $26,0 \pm 1,4$ & $25,6 \pm 1,6$ & $-3,10 * *$ & & \\
\hline PVD & $44,3 \pm 1,6$ & $43,6 \pm 1,4$ & $44,0 \pm 1,5$ & $1,44 * *$ & & \\
\hline PAD & $74,4 \pm 1,4$ & $73,6 \pm 1,5$ & $74,1 \pm 1,5$ & $1,10 * *$ & & \\
\hline DPV & $19,0 \pm 1,2$ & $17,8 \pm 1,2$ & $18,4 \pm 1,4$ & $6,10 * *$ & & \\
\hline DVA & $30,4 \pm 1,9$ & $29,9 \pm 1,7$ & $30,2 \pm 1,8$ & $1,50 *$ & & \\
\hline DFL & $22,7 \pm 2,3$ & $23,9 \pm 2,2$ & $23,3 \pm 2,3$ & $-5,11 * *$ & & \\
\hline DFB & $15,4 \pm 0,9$ & $15,8 \pm 1,0$ & $15,6 \pm 1,0$ & $-2,64 * *$ & & \\
\hline$P F L$ & $19,1 \pm 1,8$ & $19,4 \pm 1,9$ & $19,2 \pm 1,9$ & $-1,84$ & & \\
\hline VFL & $18,6 \pm 1,2$ & $19,0 \pm 1,3$ & $18,8 \pm 1,3$ & $-2,07 *$ & & \\
\hline $\mathrm{AFB}$ & $10,5 \pm 1,2$ & $11,2 \pm 1,3$ & $10,8 \pm 1,3$ & $-6,14 * *$ & & \\
\hline $\mathrm{HL}$ & $23,8 \pm 1,5$ & $24,2 \pm 1,5$ & $24,0 \pm 1,5$ & $-1,73^{*}$ & 30 & 28,6 \\
\hline \multicolumn{7}{|c|}{ Tỉ lệ so với chiè̀u dài đầu (HL, \%) } \\
\hline $\mathrm{HD}$ & $78,6 \pm 5,8$ & $75,4 \pm 5,6$ & $77,1 \pm 5,9$ & $3,99 * *$ & & \\
\hline$E D$ & $33,1 \pm 2,7$ & $33,0 \pm 2,9$ & $33,1 \pm 2,8$ & 0,55 & 23 & 25,6 \\
\hline HW & $60,5 \pm 5,7$ & $56,7 \pm 4,8$ & $58,7 \pm 5,6$ & $6,18 * *$ & & \\
\hline IOD & $50,2 \pm 4,8$ & $48,0 \pm 4,7$ & $49,2 \pm 4,9$ & $4,41 * *$ & 37 & 38,5 \\
\hline
\end{tabular}

Ghi chú: ký hiệu các chỉ tiêu nhu Hình 1. Nguồn tham khảo (1) - Mai Đình Yên và ctv., (1992); (2): Trưong Thủ Khoa và Trần Thị Thu Hưong (1993). Tỉ lệ chênh lệch giũa cá đụcc so vói cá cái (\%) có dấu * hoạc ** chỉ sụ khác biệt có ý nghĩa $(P<0,05)$ hoạc rất có ý nghĩa $(P<0,01)$ giũa hai giới tính. 
Mặc dù quan sát hình dạng bên ngoài cá cái và đực giống nhau nhưng kết hợp những khác biệt về đặc điểm sinh trưởng (mối quan hệ chiều dài - khối lượng) và chỉ tiêu sinh trắc cho thấy cá cái to hơn, có độ dày cơ thể hơn, liên quan đến đặc điểm mang trứng của con cái. Theo lý thuyết tiến hóa, kích cỡ cá cái so với cá đực phụ thuộc vào sức sinh sản và sự cạnh tranh giữa các cá đực (Parker, 1992). Chưa có thông tin về sức sinh sản của cá ba kỳ đỏ, nhưng có thể dự đoán, chúng có sức sinh sản tương tự như một số loài cá chép khác như mè vinh, cá chép,... dao động từ $100.000-300.000$ trứng $/ \mathrm{kg}$ cá cái (Nguyễn Văn Kiểm và Phạm Minh Thành, 2013). Ở các loài cá này, con cái cũng lớn hơn con đực, tương tự như cá ba kỳ đỏ. Khi mức độ cạnh tranh giữa những con đực thấp, kích cỡ con đực thường nhỏ hơn con cái (Parker, 1992) và con đực không phát triển những đặc điểm màu sắc bên ngoài để hấp dẫn con cái (Hunt et al., 2009). Điều này phù hợp với đặc điểm màu sắc cơ thể và các vi không nổi trội của con đực so với con cái ba kỳ đỏ.

Khác biệt hình dạng đầu giữa hai giới tính có thể liên quan đến tập tính di chuyển của cá. Hình dạng đầu dài hơn và nhỏ hơn ở con đực so với con cái giúp cá đực di chuyển nhanh hơn. Ở cá ba gai Gasterosteus aculeatus, chiều dài đầu của con đực lớn hơn con cái và mức độ chênh lệch phụ thuộc vào môi trường sống (Aguirre \& Akinpelu, 2010). Ngoài ra, cá đực ba kỳ đỏ có chiều dài gốc vi hậu môn lớn hơn $6,14 \%$ so với cá cái, có thể liên quan đến tập tính sinh sản như trường hợp của cá sặc rằn, sặc điệp (giống Trichopodus), con đực dùng các vi uốn cong cơ thể khi tiếp cận con cái. Tuy nhiên, do chưa có thông tin về tập tính sinh sản của cá ba kỳ đỏ nên giả thuyết trên cần được kiểm chứng trong nghiên cứu sau.

Các nghiên cứu trước (Mai Đình Yên và ctv., 1992; Trương Thủ Khoa và Trần Thị Thu Hương, 1993) chỉ báo cáo 4 đến 5 chỉ tiêu sinh trắc (Bảng 2) và không đề cập đến sự khác biệt các chỉ tiêu sinh trắc theo giới tính ở cá ba kỳ đỏ. Trong các chỉ tiêu được báo cáo, giá trị trung bình và khoảng biến động của các chỉ tiêu khác với kết quả trong nghiên cứu này, trừ chỉ số cao thân $(\mathrm{BD})$ và khoảng cách hai mắt (IOD) trùng khớp khoảng dao động với nhau. Sự chênh lệch này là do số mẫu nghiên cứu trong các báo cáo trước rất ít (4 và 5 mẫu) nên không phản ánh được mức độ biến động của các chỉ tiêu đo.

\section{KẾT LUẬN}

Các ba kỳ đỏ (tiền trưởng thành và trưởng thành) có sự khác biệt theo giới tính về kích cỡ, đường sinh trường và các chỉ tiêu sinh trắc. Trong số 15 chỉ tiêu sinh trắc (chiếm $75 \%$ các chỉ tiêu) khác nhau giữa cá đực và cá cái, khác biệt rõ nhất ở phần đầu và cao thân. Các chỉ tiêu đếm, hình dạng cơ thể và màu sắc bên ngoài giống nhau giữa hai giới.

\section{LỜI CẢM ƠN}

Đề tài này được tài trợ bởi Dự án Nâng cấp Trương Đại học Cần Thơ VN14-P6 bằng nguồn vốn vay ODA từ Chính phủ Nhật Bản.

\section{TÀI LIỆU THAM KHẢO}

Aguirre, W. E., \& Akinpelu, O. (2010). Sexual dimorphism of head morphology in three-spined stickleback Gasterosteus aculeatus. Journal of Fish Biology, 77(4), 802-821. https://doi.org/10.1111/j.10958649.2010.02705.x

Endler, J. A. (1984). Natural and sexual selection on color patterns in poeciliid fishes. In T. M. Zaret (Ed.), Evolutionary ecology of neotropical freshwater fishes (pp. 95-111). https://doi.org/10.1007/978-94-015-7682-6_7

Froese, R. (2006). Cube law, condition factor and weight-length relationships: history, metaanalysis and recommendations. Journal of Applied Ichthyology, 22, 241-253.

Hunt, J., Breuker, C. J., Sadowski, J. A., \& Moore, A. J. (2009). Male-male competition, female mate choice and their interaction: Determining total sexual selection. Journal of Evolutionary Biology, 22(1), 13-26. https://doi.org/10.1111/j.14209101.2008.01633.x

Karakulak, F. S., Erk, H., \& Bilgin, B. (2006). Length-weight relationships for 47 coastal fish species from the northern Aegean Sea, Turkey. Journal of Applied Ichthyology, 22(4), 274-278. https://doi.org/10.1111/j.14390426.2006.00736.x

Kitano, J., Mori, S., \& Peichel, C. L. (2007). Sexual Dimorphism in the External Morphology of the Threespine Stickleback (Gasterosteus Aculeatus). Copeia, 2007(2), 336-349. https://doi.org/10.1643/00458511(2007)7[336:sditem]2.0.co;2

Kottelat, M. (2001). Fishes of Laos. WHT Publications Ltd., Colombo 5, Sri Lanka.

Low, B. W., \& Lim, K. K. P. (2012). Gouramies of the genus Trichopodus in Singapore. Nature in Singapore, 5(March), 83-93.

Mei, J., \& Gui, J. F. (2015). Genetic basis and biotechnological manipulation of sexual dimorphism and sex determination in fish. Science China Life Sciences, 58, 124-136. https://doi.org/10.1007/s11427-014-4797-9 
Nguyễn Văn Kiểm \& Phạm Minh Thành (2013). Kỹ thuật sản xuất giống cá nước ngọt. Nhà xuất bản Đại học Cần Thơ.

Parker, G. A. (1992). The evolution of sexual size dimorphism in fish. Journal of Fish Biology, 41(sB), 1-20. https://doi.org/10.1111/j.10958649.1992.tb03864.x

Phạm-Thanh-Liêm, \& Trần-Đắc-Định. (2004). Giáo trình Phương pháp nghiên cứu sinh học cá. In $T u$ sách Đại hoc Cần Tho:

R_Core_Team. (2017). R: A language and environment for statistical computing. $R$ Foundation for Statistical Computing, Vienna, Austria. URL https://www.R-project.org/.

Radhi, A. M., Fazlinda, M.-F. N., Amal, M. N. A., \& Rohasliney, H. (2017). A review of length- weight relationships of freshwater fishes in Malaysia. Transylvanian Review of Systematical and Ecological Research, 20(1), 55-68. https://doi.org/10.1515/trser-2018-0005

Rainboth, W. J. (1996). Fishes of the Cambodian Mekong [Book]. In FAO species identification field guide for fishery purposes (Vol. 53, Issue 9). Food and Agriculture Organization of the United Nations (FAO), Rome, Italy. https://doi.org/10.1017/CBO9781107415324.004

Schneider, C. A., Rasband, W. S., \& Eliceiri, K. W. (2012). NIH Image to ImageJ: 25 years of image analysis. Nature Methods, 9(7), 671-675. https://doi.org/10.1038/nmeth.2089

Trương Thủ Khoa \& Trần Thị Thu Hương (1993). Định loại các loài cá nước ngọt vùng Đồng Bằng Sông Cưu Long. Trường Đại học Cần Thơ. 